The potassium chloride was not tested for purity but was assumed to be pure (theoretical $\mathrm{K}_{2} \mathrm{O}$, $6_{3}$. I 7 per cent). Whether it was pure or not does not matter so much, as aliquots from the same stock solution were used in all of the above tests.

The results indicate that the presence of sodium chloride or sodium sulfate causes low results when using 80 per cent alcohol, and that when using 92 per cent alcohol the results are practically the same whether the sodium salts are present or not. Furthermore, the fact that results are practically the same with or without the sodium salts when washing first to remove the excess platinic chloride, then with LindoGladding solution to remove sodium salts, and finally with 80 per cent alcohol, tends to prove our theory that the solution of sodium chloride or sulfate in 80 per cent alcohol does have a greater solvent action on the potassium platinic chloride than the 80 per cent alcohol alone.

As further proof another series of experiments was made. Pure potassium platinic chloride was prepared by evaporating the leachings from the crucibles in the above tests, washing thoroughly with 80 per cent alcohol, Lindo-Gladding solution, and finally with 80 per cent alcohol, and drying in an oven at $130^{\circ} \mathrm{C}$. Four grams were dissolved and diluted to $500 \mathrm{cc}$, and aliquots of $25 \mathrm{cc}$. (equal to $0.2000 \mathrm{~g}$.) were taken; a few drops of hydrochloric acid and of platinic chloride were added, together with sodium chloride and sodium sulfate as shown in Table II, and evaporated to paste as in regular potash determination. The washing was precisely the same as in the foregoing tests, except that 95 per cent alcohol replaced the 92 per cent alcohol used in the previous tests. Also, denatured alcohol, Formula 30, was used. The results shown in Table II, giving grams of $\mathrm{K}_{2} \mathrm{PtCl}_{6}$ found, are in every case the average of two or three determinations.

\begin{tabular}{|c|c|c|c|}
\hline & TABLE I & & \\
\hline & $\begin{array}{l}80 \text { Per cent } \\
\text { Alcohol } \\
\text { Grams }\end{array}$ & $\begin{array}{l}95 \text { Per cent } \\
\text { Alcohol } \\
\text { Gratns }\end{array}$ & $\begin{array}{c}\text { Alcohol First, } \\
80 \text { Per cent } \\
\text { Alcohol Last } \\
\text { Grams }\end{array}$ \\
\hline $\mathrm{K}_{2} P_{C l} \mathrm{l}_{\text {alone }}$ & 0.1999 & 0.2009 & 0.2018 \\
\hline $\begin{array}{l}0.1 \mathrm{~g} . \mathrm{NaCl} \text { added. } \\
0.2 \mathrm{gaCl} \text { added. }\end{array}$ & $: \quad 0.1978$ & $\begin{array}{l}0.2017 \\
0.2025\end{array}$ & $\begin{array}{l}0.2007 \\
0.2005\end{array}$ \\
\hline $0.4 \mathrm{~g}$. NaCl added. & $\begin{array}{l}0.1960 \\
\end{array}$ & $\begin{array}{l}0.2002 \\
0.2012\end{array}$ & $\begin{array}{l}0.2002 \\
0.2013\end{array}$ \\
\hline $0.2 \mathrm{~g} . \mathrm{Na}_{2} \mathrm{SO}_{1}$ added. & 0.1988 & 0.2020 & 0.2009 \\
\hline $\begin{array}{l}0.4 \mathrm{~g} . \mathrm{Na}_{2} \mathrm{SO}_{4} \text { added } \\
0.05 \mathrm{~g} \text {. NaCl }+0.05 \mathrm{~g}\end{array}$ & 0.1985 & 0.2009 & 0.2007 \\
\hline $\mathrm{Na}_{2} \mathrm{SO}_{4}$ added $\ldots \ldots$ & 0.1995 & 0.2011 & 0.1999 \\
\hline $\mathrm{Na}_{2} \mathrm{SO}_{4}$ added...... & 0.1983 & 0.2006 & 0.2009 \\
\hline$\cdot \mathrm{Na}_{2} \mathrm{SOO}_{4} \mathrm{Nadded}^{\mathrm{NaCl}}+\ldots .2 \ldots$ & 0.1957 & 0.2004 & 0.2012 \\
\hline
\end{tabular}

In these results the sodium chloride causes slightly lower results than the sulfate. This condition is somewhat different from those in Table I, as in that case the potassium salt also was converted to stlfate, thus yielding some free sulfuric acid after evaporation, whereas in Table II no free sulfuric acid would be formed in any case. Otherwise these data confirm those in the first table.

No very complete study of the effect of various salts or the strength of the alcohol used in washing is covered by the results given above, but sufficient has been done to warrant the further careful study of this subject. The effect of other salts, such as those of calcium and magnesium, should be included. The data do seem to warrant the suggestion that the official method be changed at least to allow the use of the strong alcohol, about 95 per cent, for the first washings to remove excess platinic chloride, and the 80 per cent alcohol for final washing, if this is considered necessary; then if there is anything present which 80 per cent alcohol should remove and which 95 per cent alcohol will not remove, it can be done in the final washing without including the effect of sodium or other salts.

Unfortunately all analysts have not followed the official method in the use of 80 per cent alcohol. This includes some works laboratories as well as referees. Some use strong alcohol altogether, some Columbian spirits (about 96 per cent), while others have faithfully followed the official method in using 80 per cent alcohol as prescribed, thereby finding lower percentages of potash. While the results obtained by using stronger alcohol are nearer the true values, as judged from the foregoing at least, the fact remains that the official method specifies 80 per cent alcohol, and all laboratories making this determination should be governed accordingly until the method is changed.

Fertilizer chemists have been aware for some time that the results obtained on analyses of mixed fertilizers, even on carefully prepared laboratory samples, are lower than the results calculated from the analyses of the potash salts used. This has been largely attributed either to the formation of some insoluble potassium silicate or to the selective absorption of the calcium oxalate or phosphate precipitate for salts of potassium. How much is really due to either of these causes, and how much to the strength of the alcohol, is unknown, as 80 per cent alcohol has been used when making study of this problem.

Our own results have usually indicated a loss of from 2 per cent to 3 per cent of the potash as calculated, and this is no small item to the fertilizer manufacturer, who deserves credit for all of the potash added.

\section{THE DETECTION OF OILS OTHER THAN LINSEED IN PAINTS BY MEANS OF THE HEXABROMIDE NUMBER OF THE FATTY ACIDS ${ }^{1}$ \\ By Herbert Bailey and Walter D. Baldsiefen}

Experimental Statron, E. I. DU Pont de Nemours \& Co., HENRY Clay, DeLAWARE

The abnormally high price of linseed oil during the last two years has naturally increased interest in methods for detecting adulteration of this basic paint material. Messrs. Steele and Washburn ${ }^{2}$ in their recent article on "A New Hexabromide Method for Linseed Oil" have most ably covered the more important work on hexabromide methods. In using the modification of Eibner's method $^{3}$ proposed by Steele and Washburn, which was submitted for cooperative work to members of Committee D-I of the

1 Presented in part before the Division of Agricultural and Food Chemistry at the 59th Meeting of the American Chemical Society, St. Louis, Mo., April 12 to 16, 1920.

2 Thus Journal, 12 (1920), 52.

3 Farben-Ztg., Nov. 23, 1912 (No. 8). 
A. S. T. M., the authors have felt that there was room for further simplification in the procedure. In the hope that under properly controlled conditions it would be possible to get concordant results without separating the fatty acids, $i$. e., by brominating the glycerides, the procedure adopted by Bailey and Johnson in their work on salmon oil ${ }^{1}$ was studied. A fairly complete investigation has proved, however, that it is necessary to add the bromine to the fatty acids in order to get results of any value in detecting the presence of foreign oils in linseed. In our method, therefore, we have adopted a procedure similar to that recommended by Steele and Washburn for the preparation of the fatty acids. As a solvent for the fatty acids we very much prefer ether to chloroform, as in the latter the hexabromides are quite soluble, and the chloroform must therefore be completely removed before they can be precipitated. Work of previous investigators, especially Sutcliffe, ${ }^{2}$ has pretty conclusively demonstrated that under properly controlled conditions the hexabromides of the unsaturated fatty acids can be quantitatively separated from ether solutions. Another advantage which will appeal to the works chemist is that when ether is used it is unnecessary to prepare a special chloroform as in the Steele-Washburn method, and a slight excess of bromine does not affect the final results, so that it is not necessary, to use amylene or other reagents to neutralize the excess added in the brominating process. It is essential, however, that an ether saturated with linseed oil hexabromides be employed, as they have a slight though appreciable solubility even at $0^{\circ} \mathrm{C}$.

\section{BROMINATING REAGENT}

Bailey and Johnson found it much more convenient to add the bromine in acetic acid solution than as the pure element. Gemmell, ${ }^{3}$ in his review of the work of earlier investigators on the insoluble bromine value of oils, pointed out that the amount of acetic acid present materially affects the weight of bromides obtained. Presumably there is some optimum mixture of ether and acetic acid which will be most satisfactory as the bromination solvent. Freyer and Weston ${ }^{4}$ recommended $2 \mathrm{cc}$. of glacial acetic acid and $20 \mathrm{cc}$. of anhydrous ether. We found that when $20 \mathrm{cc}$. of ether and $4 \mathrm{cc}$. of acetic acid were used in a determination, our pure linseed oil gave hexabromide values of 42.8 and 44.4 , while with $25 \mathrm{cc}$. of ether and the same amount of acid the results were 43.9 and 44.3 . This indicated that not only more concordant results but also slightly higher values were obtained when the percentage of ether in the mixture was increased. As I g. of linseed oil fatty acids requires about $0.5 \mathrm{cc}$. of bromine to saturate them, and $30 \mathrm{cc}$. is a convenient volume in which to carry out the bromination, a 20 per cent (by volume) glacial acetic acid solution of bromine has been adopted as the brominating reagent, and $25 \mathrm{cc}$. of ether plus $2 \mathrm{cc}$. of acetic acid as the solvent in which to dissolve the fatty acids. This gives in the

I This Joursal, 10 (1918), 999

2 The Anclyst, 39 (1914), 28.

3 Ibid., $\mathbf{3 9}$ (1914), 297.

" "Technical Handbook of Oils, Fats and Waxes." Cambridge, $2(1918), 111$. final solution of fatty acids, bromides, ether, and acetic acid, approximately 13 per cent of the acetic acid, or practically the same as recommended by Freyer and Weston.

\section{BROMINATION PROCEDURE}

EFFECT OF TEMPERATURE OF BROMINATION-In this work the temperature of the ether solution of fatty acid has been kept about - $10^{\circ} \mathrm{C}$. by immersion in a small bath of chopped ice and hydrochloric acid. In a series of determinations on two samples of mixed fatty acids two brominations of each were made at $0^{\circ} \mathrm{C}$. and two at $-\mathrm{ro} 0^{\circ} \mathrm{C}$. Those at $0^{\circ} \mathrm{C}$. gave values for Sample A of $35 . \mathrm{I}$ and 37.9 , and for $\mathrm{B}$ of 35.7 and 36.6 , a variation in the first two of 2.8 and in the second 0.9 . At $-10^{\circ} \mathrm{C}$. the hexabromide values were $36.3,37.5$ and $37.2,37.6$, respectively, showing a discrepancy of $I .2$ on Sample $A$ and only 0.4 on $B$. While the data obtained were too meager to warrant any very definite statement with reference to the effect of temperature on the bromination, they were sufficient to convince us that it is safer to work at $-10^{\circ} \mathrm{C}$. than at $0^{\circ} \mathrm{C}$.

EFFECT OF RATE OF BROMINATION-Many previous investigators have mentioned the importance of allowing sufficient time after the addition of the bromine to the fatty acids for complete precipitation of the hexabromides, but little attention has been paid to the rate at which the brominating reagent is added. Although Bailey and Johnson had confirmed the statement of Sutcliffe that the best results were obtained by allowing the brominated mixture to stand over night, we made one series of determinations in which this point was investigated. It was found that the same fatty acids precipitated in the same way gave values of 39.7 if filtered and washed after standing 3 hrs., 40.7 after $6 \mathrm{hrs}$., and 43.0 when allowed to stand over night ( $\mathrm{r} 6 \mathrm{hrs}$.) in the ice box. Apparently there is a continued increase in the formation of ether-insoluble bromides with increased time of standing, but this we believe is not due to the substitution of bromine in the chain, as only a trace of free hydrobromic acid could be detected even in the solution which had stood over night.

Experiments in which the same linseed oil acids were treated with the same amount of the acetic acid solution of bromine under identical conditions, with the exception of the rate at which the bromine reagent was added, proved that this has some effect upon the yield of brominated products. Using $4 \mathrm{cc}$. of the reagent, a rather large excess, in each case, when the addition took place in $3 \mathrm{~min}$., the hexabromide value found was 43.9 , in to $\mathrm{min} .46 .9$, and in $30 \mathrm{~min} .48 .2$. Another sample of fatty acids was treated with 2.7 cc. of the bromine reagent (which was just sufficient to give a slight excess of bromine as shown by the permanent yellow color), and the rate of addition had much less effect on the final results. Pouring in the entire $2.7 \mathrm{cc}$. of * solution all at once, we obtained 43.I and 43.2 as the hexabromide values, and when the reagent was dropped in slowly from a buret during the course of Io min., the values were 44.8 and 44.9 . In both sets of experiments the brominated solutions 
were allowed to stand over night in the ice chest before filtering and washing:

\section{DETAILED DESCRIPTION OF METHOD}

REAGENTS-The following reagents in about the quantities mentioned will be required for making ten determinations:

Sodium Hydroxide Solution ( $1.4 \mathrm{sp}$. gr.)-Dissolve $75 \mathrm{~g}$. of C. P. NaOH in water and make up to $200 \mathrm{cc}$.

Alcohol ( 95 per cent by volume)-200 cc. (denatured alcohol is satisfactory).

Hydrochloric Acid-C. P., concentrated, $300 \mathrm{cc}$.

Glacial Acetic Acid-2o cc. This acid should not show any reduction in the usual bichromate or permanganate tests.

Glacial Acetic Acid Solution of Bromine-30 cc. Five cc. of bromine $+25 \mathrm{cc}$. of acetic acid. The bromine must be free from non-volatile matter.

Ether Saturated at $o^{\circ} \mathrm{C}$. with Linseed Oil Hexabromides - Wash in a separatory funnel a liter of laboratory ethyl ether with four successive roo-cc. portions of distilled water (ice-cold) and dry with fused calcium chloride over night. In the morning, pour the ether off through a folded filter paper into a I.5-or 2-liter flask. Add several thin slices of sodium, reflux until there is no longer any evidence of the liberation of hydrogen, then distil off the dry ether.

Before the ether can be used it must be saturated at 0 " C. with the hexabromides of linseed oil fatty acids to prevent its dissolving hexabromides during the washing of the bromination products in the determination. To prepare the hexabromides for this purpose, the directions given below have been found very satisfactory:

In a centrifuge tube dissolve about $5 \mathrm{~g}$. of the fatty acids in $25 \mathrm{cc}$. of ether. Place the tube in a freezing mixture and add slowly, with shaking, bromine solution, until a red color is permanent. Let stand for at least I 5 min., whirl the tube in a centrifuge until the precipitate has settled, and then pour off the ether. Rub up the precipitate with $20 \mathrm{cc}$. of cold absolute ether, whirl in a centrifuge, and pour off the wash ether. Repeat the washing with three more 20 -cc. portions of ether. After drying, the hexabromide so obtained is pure enough for the preparation of the wash ether.

To saturate the dry ether with the hexabromides thus prepared or those from previous determinations made of pure linseed oils, which should always be saved, add at least $3 \mathrm{~g}$. of the finely powdered substance and allow the solution to stand at room temperature with frequent shaking for several hours. Cool in ice water for 2 hrs., shaking from time to time, and finally filter as rapidly as possible into a dry corkstoppered bottle.

APPARATUS-In addition to the ordinary equipment of a chemical laboratory, it is essential for the proper handling of this method that one, have the following apparatus:

(a) Twelve centrifuge tubes about $\mathrm{I} \times 5$ in., of wellannealed heavy glass.

(b) A laboratory centrifuge with cups for holding the above centrifuge tubes.
Determination. Preparation of the Fatiy Acids -To $50 \mathrm{cc}$. of oil in a 2-liter, round-bottom flask, add $40 \mathrm{cc}$. of $\mathrm{NaOH}$ solution (sp. gr. I.4 $=36.50$ per cent $\mathrm{NaOH}$ ) and $40 \mathrm{cc}$. of alcohol. Close the flask with a 2-hole rubber stopper, carrying a quarter-inch tube, the lower end of which is just above the surface of the liquid, and heat on the steam bath for about $0.5 \mathrm{hr}$. Add a liter of hot distilled water and boil the soap solution until the alcohol is removed, passing a stream of $\mathrm{CO}_{2}$ continually through the inlet tube. If a free flame is used, about $0.5 \mathrm{hr}$. boiling. will be sufficient, but in this case it may be necessary to insert capillary tubes to prevent bumping of the liquid. If the solution is heated on the steam bath, 2 to 3 hrs. are usually required. After removing the alcohol, cool slightly, acidify with dilute $\mathrm{HCl}(\mathrm{r}: \mathrm{I}$ ), and warm until the fatty acids form a clear layer (continuing to pass $\mathrm{CO}_{2}$ through the system all the time). Transfer the fatty acids and part of the solution to a 500-cc. separatory funnel, allow to stand a few minutes until the fatty acids collect on top of the aqueous portion, and draw this off. Pour the remainder of the mixture from the flask into the funnel, and run off the aqueous portion. Add $300 \mathrm{cc}$. of hot water, shake vigorously, allow the fatty acids to separate, and again draw off the aqueous portion. Repeat this process until the wash water is neutral to methyl orange, three washings usually being sufficient. Run the warm fatty acids at once into a centrifuge tube and whirl for about a minute to separate the remaining water, then filter through a folded filter paper into a small bottle. When the major portion of the acids have run through the filter, discard the remainder, and stopper the bottle with a tight cork. It is obvious that the acids must be hot enough when poured on the filter to remain completely liquid until filtered, as otherwise some of those with a high melting point may separate.

Precipitation of the Hexabromides-Weigh accurately one of the centrifuge tubes, pipet into it as nearly as practicable $\mathrm{I.00} \mathrm{g}$. of the prepared fatty acids and again weigh. For transferring the fatty acid, a piece of $5 \mathrm{~mm}$. glass tubing about $20 \mathrm{~cm}$. long, drawn out to a tip and bent down at the lower end and up at the other in a shape similar to a "S" wrench, is convenient. To the fatty acids in the centrifuge tube add $25 \mathrm{cc}$. of the ether saturated with hexabromides and $2 \mathrm{cc}$. of glacial acetic acid. Cool the tube and its contents to about - Io $0^{\circ} \mathrm{C}$. by immersion in a bath of chopped ice to which a little commercial hydrochloric acid has been added; then, keeping the tube in the cooling mixture, add from a buret the bromine reagent at the rate of one or two drops per second, shaking the tube after each addition. Continue the bromination. until the solution of fatty acids becomes permanently orange in color (usually for pure linseed oil this requires about $2.5 \mathrm{cc}$.), then remove the tube from the bath, stopper it with a cork, and allow to stand over night in an ice box.

Washing and Weighing of the Hexabromides-Next morning cool the tube by immersion in a bath of cracked ice and rub up the precipitate by means of a weighed glass rod, being sure to loosen any material 
adhering to the side of the tube. Whirl the tube in a centrifuge till the precipitate forms a hard cake on the bottom, cool in the ice bath, and decant the ether. Add $20 \mathrm{cc}$. of the wash ether previously cooled to $0^{\circ} \mathrm{C}$. and rub up the precipitate with the glass rod. Return the tube to the ice bath and when cool remove and whirl again in the centrifuge. Cool once more and then remove the ether by decantation. Repeat this washing twice more, and after the last washing incline the tube and carefully tap it to spread the hexabromide precipitate part way up the sides. Warm the tube in water at $60^{\circ} \mathrm{C}$. until most of the ether has evaporated, then attach it for ${ }_{5} \mathrm{~min}$. to a vacuum line showing a pressure of 30 to $40 \mathrm{~mm}$., keeping the temperature around $60^{\circ} \mathrm{C}$. Wipe the tube dry and allow it to stand in the balance at least $x_{5} \mathrm{~min}$. before weighing. To the weight of the precipitate in the tube add the weight of the slight amount adhering to the glass rod. This total weight of precipitate, multiplied by 100 and divided by the weight of the fatty acids taken, gives the hexabromide percentage.

RESULTS OBTAINED ON PURE LINSEED AND OTHER OILS

PURE LINSEED OILS-Unfortunately only a very few samples of pure linseed oil were available for this work, but these were analyzed, with the results given in Table $I$.

TABLE I-IONINE AND HEXABROMIDE VALUES OF PURE LINSEED OILS Sample Number......... Hexabromide Valtue.....

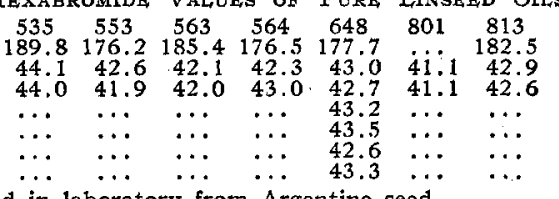

No. 535-Oil extracted in laboratory from Argentine seed No. 553-Oil extracted with gasoline on commercial scale from North American seed

No. 563 -Commercial raw oil

No. 564 -Commercial acid refined oil

No. 648 -Pure raw oil (atthentic A.S.T.M. sample)

No. 801 -Oil extracted in lahoratory from Argentine seed

No. 813-Commercial taw oil

The figures in Table I are of interest, because they demonstrate, to a limited extent, it is true, the value of the hexabromide number as a basis for judging the purity of linseed oil. The iodine values of the oils examined vary from I 76 to 189 , I 3 points, while the maximum difference in the hexabromide values is 3 , from 4I.I to 44.I. This narrow spread in these socalled "constants" is, of itself, perhaps insufficient to warrant the substitution of the more difficultly obtained hexabromide value for the now almost universally accepted iodine value, but when considered with the values of these same constants for the oils commonly used to adulterate linseed oil it is of great importance. Discussion of this point will be taken up after Tables II and III, which give our results on treated linseed oils, soy-bean, fish and tung oils, have been considered. That the method which has been proposed for determining the hexabromide value is capable of giving results agreeing among themselves within about 2 per cent, is evidenced by the figures obtained on Sample 648 .

TREATED LINSEED OILS-It is one thing to detect adulteration of pure raw linseed oils and quite another to determine the purity of "boiled," "heavy bodied," or "bung-hole boiled" oils. To ascertain the effect on the hexabromide value of the various treatments to which linseed oils are subjected in the preparation of commercial products, such as varnish and lithographic oils, we analyzed a number of samples representative of these classes. The results are shown in Table II.

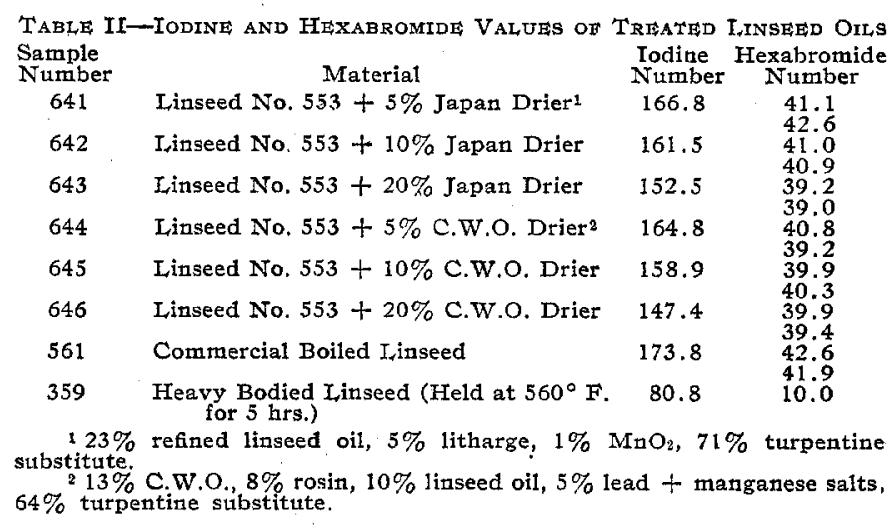

The Japan drier used in Samples 64I to 643 was really a mixing varnish and very evidently did not have any appreciable influence on the linseed oil with which it was mixed, other than mere dilution. Even after standing for three months these oils had not changed appreciably in their hexabromide values. Samples 644 to 646 , which contained the China wood oil drier, were similarly unaffected, although their iodine numbers were reduced more than in the case of the first series.

So far we have had time to test only one true boiled oil, that is, a linseed oil to which had been added a small amount of lead and manganese in the form of their fatty acid soaps by heating the mixture at $250^{\circ} \mathrm{F}$. until homogeneous. In this instance, Sample $56 \mathrm{I}$, neither the iodine nor hexabromide value differed from that for a pure raw oil. That the oxidation which takes place in bodying an oil very materially affects both the iodine and hexabromide values, as would be expected, is indicated by the results on Sample 359 . The best commercial practice for the production of "boiled oil" does not involve any appreciable heating, as the metallic driers are nowadays usually fatty acid soaps, and, therefore, readily soluble in the oil. The older method for making boiled oils, which necessitated prolonged heating of the raw oil above $400^{\circ}$ F. with an oxide or other inorganic salt of the metal, often caused not only a darkening of the oil, but an appreciable lowering of its iodine value. Where this older process is used, we have found that there is a decrease in the hexabromide value along with the iodine value.

There is some indication that the changes taking place in linseed oil during oxidation with air at high temperatures $\left(400^{\circ} \mathrm{F}\right.$ ) do not affect the hexabromide value and iodine value to the same extent. Some preliminary work makes it appear possible that, by determining both of these constants and getting the relation between them, a factor may be found which will make practicable the differentiation between pure oxidized or heavy-bodied linseed oils and mixtures of these with other oils. 
OIIS OTHER THAN PURE LINSEED-The most common substitutes for linseed are soy bean, fish, and (in a sense) tung, although the last at the present time is used to supplement rather than replace linseed. In Table III will be found the hexabromide values of a few samples of these oils and mixtures of soy-bean and linseed oils.

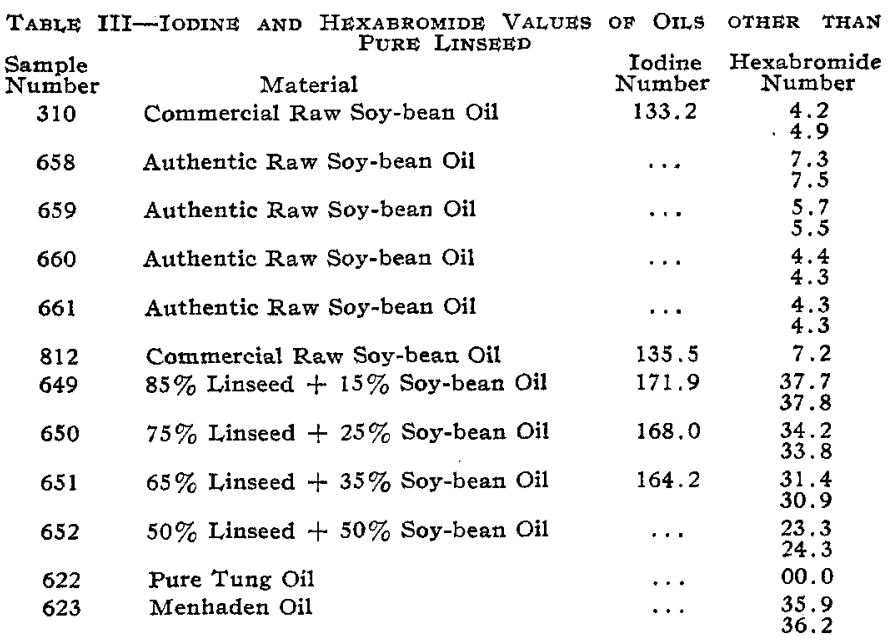

By our method, the hexabromide value of pure soybean oil averages about 6.0 , varying from 4.2 to 7.5 , tung oil gives no ether-insoluble bromine derivatives, and fish oils yield octobromides which are insoluble in warm chloroform, and, therefore, readily distinguishable from the hexabromides. The melting point of the linseed hexabromides is about I $80^{\circ} \mathrm{C}$., while the fish-oil octobromides decompose at $200^{\circ} \mathrm{C}$. without melting. It is well, therefore, to test the bromides after the final weighing by warming them gently. If they blacken, indicating the presence of fish oil octobromides, they may then be treated with hot chloroform which will dissolve all the hexabromides, leaving the insoluble octobromides which can be weighed. The details of this procedure have not been worked out, but anyone having occasion to make the separation can undoubtedly develop a method with little difficulty.

QUANTITATIVE APPLICATION OF THE METHOD-Using the figures given in Table III for Samples 649 to $65_{2}$, which were of known composition, and the average hexabromide values of 42.0 and 6.0 for linseed and soy-bean oils, respectively, it is interesting to note the nearness with which the actual proportions of the two oils may be calculated. For Sample 649, taking the average value of 37.75 , we get 88.2 per cent linseed and I 1.8 per cent soy-bean oil, against 85 and 15 per cent actually present. Similarly for Sample 650 , the proportions found are 77.7 per cent linseed and 22.3 per cent soy-bean, present 75 and 25 per cent; found for Sample 65I, 69.8 per cent linseed and 30.2 per cent soy-bean, present 65 and 35 per cent; and in Sample 652, which contained equal parts of the two oils, we found 49.4 per cent linseed and 50.6 per cent soy-bean oil.

HEXABROMIDE VALUE OF OILS FROM COMMERCIAL PAINTS

The crucial test of the real value of the hexabromide method is in its application to the analyses of com- mercial paints. We have shown that the addition of substitutes to linseed oils cannot only be detected with a fair degree of accuracy, but also quantitatively determined, and the next question is how far this method is reliable with ordinary paints. Work on this phase of the subject has been started, but much more is needed before definite conclusions can be drawn with reference to the effect of various pigments, Japan driers, and other normal paint ingredients. In Table IV are collected the results obtained on a few paste colors, and paints of known and unknown composition.

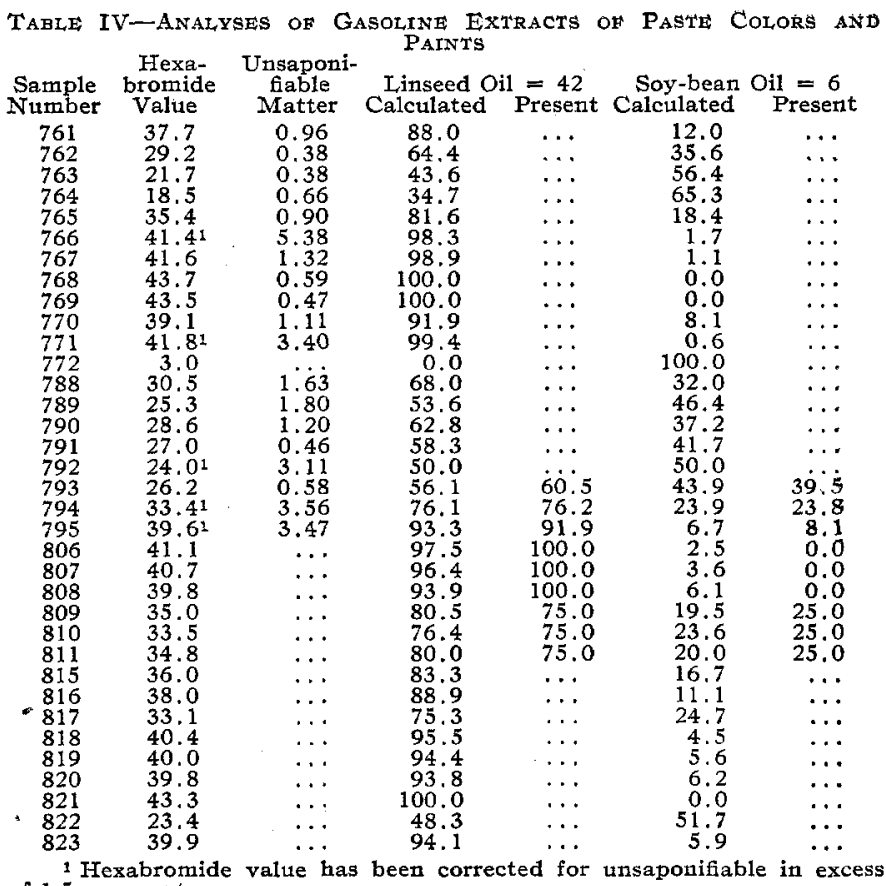
of 1.5 per cent.

The figures given in Columns 4 and 6 are calculated from the hexabromide values found, on the assumption that the average linseed hexabromide value is 42 , that of soy bean 6 , and that of the unsaponifiable zero. The normal content of unsaponifiable matter in linseed oil is about $x .0$ per cent, and where not over I.5 per cent was found in the fatty acids taken for analysis, we have assumed that only saponifiable oils were present in the original paint, and, therefore, applied no correction in these cases. In view of the limited amount of data which has been collected on this part of our investigation, we are hardly warranted in drawing any more than the general conclusion that Samples 761 to $765,772,788$ to 795 , and 809 to $8 I 7$, all of which have a corrected hexabromide value of 39 or less, undoubtedly contain oils other than pure raw linseed.

Some idea of the degree of accuracy with which the relative proportions of linseed and soy-bean oils can be determined by the proposed method may be obtained from the results on paint samples of known composition, reported in Table IV. These Samples 793 to $8 \mathrm{x} x$ were made in a small paint mill, and duplicate as nearly as possible commercial colors found on the market. The tabulated results indicate that it is possible by the hexabromide value to determine 